\title{
Elaboração de bebida com extrato hidrossolúvel de soja saborizada com frutos do Cerrado
}

\author{
Danielle Godinho Araújo Perfeito ${ }^{1}$, Ivna Moreira Corrêa ${ }^{1}$, Nei Peixoto \\ ${ }^{1}$ Instituto Federal Goiano - IFGoiano, Câmpus Urutaí, GO, Brasil. E-mail: daniellegodinhoaraujo@ hotmail.com, \\ ivnacorrea@hotmail.com \\ ${ }^{2}$ Universidade Estadual de Goiás - UEG, Câmpus de Ipameri, GO, Brasil. E-mail: nei.peixoto48@gmail.com
}

Recebido: 13/08/2016; Aceito: 21/11/2016.

\section{RESUMO}

Os frutos do Cerrado apresentam atrativas características sensoriais, porém seu consumo é restrito à população local. Visando contribuir para expansão do consumo de cagaita e mangaba, o objetivo do estudo foi elaborar e avaliar a aceitação de bebidas com extrato hidrossolúvel de soja saborizada com esses frutos. Para isso elaborouse três formulações tendo como base fixa 10\% de polpa de fruta e 15\% de açúcar, sendo Formulação 1: 10\% de polpa de mangaba, Formulação 2: 10\% de polpa de cagaita e Formulação 3: 5\% de cagaita e 5\% de mangaba. Realizou-se a caracterização físico-química tanto das polpas como das bebidas. Estas foram submetidas às análises de pH, acidez total titulável (AT), sólidos solúveis (SS), relação SS/AT, sólidos totais e cinzas. Para a avaliação sensorial, cinquenta consumidores não treinados avaliaram aparência, aroma, sabor, textura e impressão global, além da intenção de compra. Os resultados das análises físico-química de ambas amostras foram satisfatórios, apresentando parâmetros desejáveis e esperados. Em relação aos atributos sensoriais avaliados, a Formulação 3 (5\% de cagaita e 5\% de mangaba) obteve uma boa aceitação para os atributos aroma, sabor e impressão global, quando comparada às outras formulações. Além de maiores percentuais no quesito intenção de compra. A elaboração da bebida mostrou-se viável e certamente trata-se de uma opção a mais tanto aos intolerantes à lactose quanto aos alérgicos à proteína do leite de vaca.

Palavras-chave: Cagaita, mangaba, tecnologia de alimentos, teste de aceitação

\section{Beverage preparation with extract soluble soybean flavored with fruits of the cerrado}

\begin{abstract}
The fruits of the Cerrado has attractive sensory characteristics, but its use is restricted to the local population. To contribute to the expansion of consumption and cagaita mangaba, the goal of the study was to develop and evaluate the acceptance of beverages with water soluble extract of soy flavored with these fruits. To this was elaborated three formulations based on fixed 10\% fruit pulp and 15\% sugar, Formulation 1: 10\% mangaba pulp, Formulation 2: $10 \%$ cagaita pulp e Formulation 3: 5\% cagaita e 5\% mangaba pulps. It held the physicochemical characterization of both pulps and drinks. These were submitted to $\mathrm{pH}$, titratable acidity, soluble solids ( ${ }^{\circ}$ Brix $)$, ratio (SS/TA), total solids and ash. For sensory evaluation, consumer fifty untrained evaluated appearance, aroma, flavor, texture and overall impression, as well as purchase intent. The results of physicochemical analyzes of both samples were satisfactory, with desirable and expected parameters. Regarding the sensory attributes evaluated, Formulation 3 (5\% cagaita and 5\% mangaba) obtained a good acceptance for flavor, taste and overall impression compared to other formulations. In addition to higher percentages in the category purchase intent. The drink proved to be feasible and certainly this is one more option to both lactose intolerant as the allergy to cow's milk protein.
\end{abstract}

Key words: Cagaita, mangaba, food technology, acceptance test. 


\section{Introdução}

O Cerrado é o segundo maior bioma do Brasil; ocupa $24 \%$ do território nacional. No Cerrado são encontradas muitas espécies de plantas utilizadas na alimentação humana como cagaita, pequi, baru, cajuzinhos, maracujás nativos, jatobá, mangaba, buriti, coquinho azedo e babaçu. (SCARIOT; RIBEIRO, 2015). Os frutos do Cerrado apresentam sabor peculiar e elevado teor de açúcar, proteínas, sais minerais e ácidos graxos (SILVA et al., 2001).

A mangabeira (Hancornia speciosa Gomes) é uma fruteira pertencente à família Apocynaceae, nativa do Brasil e está presente nas regiões Centro-Oeste, Sudeste, Norte e Nordeste nas áreas do Cerrado e Caatinga. (VENTURINI FILHO, 2010). A cagaiteira (Eugenia dysenterica), planta arbórea que destaca-se pela alta capacidade de produção (500 - 2000 frutos por planta), produz um fruto amarelo, globoso e achatado, com polpa de sabor acidulado e grande suculência (SILVA; TASSARA 2003).

O interesse na utilização de proteínas vegetais e seus derivados na indústria de alimentos têm crescido nos últimos anos. A soja, devido às suas qualidades nutricionais e funcionais, disponibilidade de mercado, baixo custo e desenvolvimento de tecnologia apropriada, apresenta um consumo crescente entre os povos ocidentais (MARTINS, 2005). O extrato hidrossolúvel de soja (EHS), conhecido também como "leite" de soja, livre de lactose, pode substituir o leite de vaca na alimentação de pessoas alérgicas ou intolerantes ao açúcar do leite bovino.

Os frutos do cerrado oferecem um alto valor nutricional, além de alguns atributos sensoriais convidativos como: cor, aroma e sabor intenso. Apesar de suas particularidades ainda são pouco utilizados comercialmente tanto in natura como industrializados e combinados com outros produtos. Por esta afirmação, objetivou-se desenvolver a tecnologia e avaliar formulações de uma bebida com extrato hidrossolúvel de soja (EHS) saborizada com cagaita e mangaba, combinando o sabor exótico de uma fruta do cerrado ao extrato hidrossolúvel de soja, oferecendo mais uma alternativa para o consumo do extrato hidrossolúvel de soja.

\section{Material e Métodos}

Os frutos da cagaiteira e mangabeira foram colhidos na Universidade Estadual de Goiás - Unidade Universitária de Ipameri, região Sudeste de Goiás, no período de novembro a dezembro de 2015 e transportadas via terrestre em caixas de plástico para a Planta de Processamento de Frutas e Hortaliças do Instituto Federal Goiano - Campus Urutaí. Os frutos foram lavados e sanitizados em solução de hipoclorito de sódio (200 mg. $\left.\mathrm{L}^{-1}\right)$ por 15 minutos com sequente enxágue. As cagaitas e mangabas foram armazenadas em sacos de polietileno de $2 \mathrm{~kg}$ (lotes) e congelados para posteriores despolpamentos.

Os frutos foram descongelados e as polpas obtidas em despolpador tipo pás utilizando peneira de $0,8 \mathrm{~mm}$ de diâmetro de abertura de malha. As polpas de cagaita e mangaba foram homogeneizadas e acondicionadas separadamente em sacos de polietileno contendo cerca de $500 \mathrm{~g}$ de polpa. As polpas foram congeladas e mantidas em freezer, na Unidade de Processamento de Frutas e Hortaliças do IF Goiano Campus Urutaí, a -18 ${ }^{\circ} \mathrm{C}$ para posterior caracterização e elaboração das bebidas. As polpas foram caracterizadas em triplicata quanto à: teor de sólidos totais, determinado por secagem em estufa a $105^{\circ} \mathrm{C}$ segundo método $\mathrm{n}^{\circ} 920.151$ da AOAC (1997); acidez total titulável (ATT), segundo método $\mathrm{n}^{\circ} 942.15$ da AOAC (1997) e expressa em porcentagem de ácido cítrico; $\mathrm{pH}$, medido em potenciômetro calibrado com soluções-tampão nos pHs 4 e 7 a $20^{\circ} \mathrm{C}$, segundo método $\mathrm{n}^{\circ} 981.12$ da AOAC (1997); sólidos solúveis ( ${ }^{\circ}$ Brix), baseado na leitura direta dos graus Brix da amostra a $20^{\circ} \mathrm{C}$ em refratômetro digital; ratio quociente entre teor de sólidos solúveis e acidez total titulável; teor de cinzas por incineração em mufla a $550{ }^{\circ} \mathrm{C}$.

A bebida foi preparada (Figura 1) utilizando $10 \%$ de polpa de fruta e $15 \%$ de açúcar diluído em extrato hidrossolúvel de soja (EHS) comercial (Ades Original). Preparou-se três formulações sendo: Formulação 1 com $10 \%$ de polpa de mangaba, Formulação 2 com $10 \%$ de polpa de cagaita e a Formulação 3 com $5 \%$ de cagaita e $5 \%$ de mangaba. As bebidas foram submetidas ao aquecimento até $85{ }^{\circ} \mathrm{C}$ e envasadas a quente, sendo acondicionadas em garrafas de vidro de $500 \mathrm{~mL}$, previamente sanitizadas com solução de hipoclorito de sódio $\left(50 \mathrm{mg} \mathrm{L}^{-1}\right)$. As garrafas foram invertidas, durante 5 minutos, para assegurar que o produto quente entre em contato com a parte superior da embalagem bem como a tampa sendo resfriadas logo em seguida pela imersão em água e depois acondicionadas em temperatura de refrigeração.

As formulações das bebidas de cagaita e mangaba foram caracterizadas, em triplicata, em relação ao teor de sólidos totais, determinado por secagem em estufa a $105^{\circ} \mathrm{C}$, segundo método $\mathrm{n}^{\circ} 920.151$ da AOAC (1997); acidez total titulável, segundo método $\mathrm{n}^{\circ} 942.15$ da AOAC (1997) e expressa em porcentagem de ácido cítrico; $\mathrm{pH}$, segundo método $\mathrm{n}^{\circ} 981.12$ da AOAC (1997); sólidos solúveis ( ${ }^{\circ}$ Brix), baseado na leitura direta dos graus Brix da amostra a $20^{\circ} \mathrm{C}$ em refratômetro digital; relação entre teor de sólidos solúveis e acidez total titulável; teor de cinzas por incineração em mufla a $550{ }^{\circ} \mathrm{C}$. 


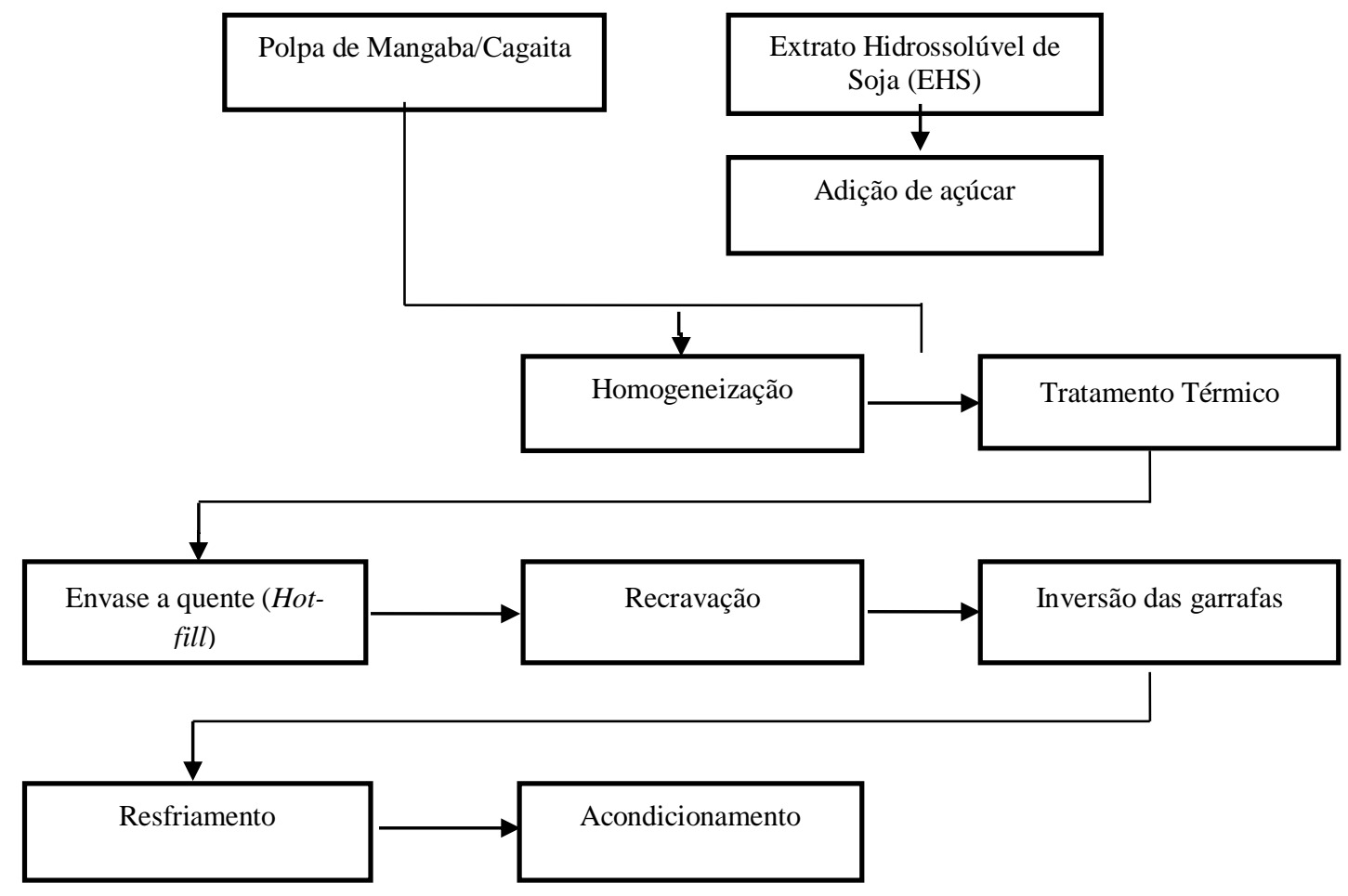

Figura 1: Fluxograma do processo de obtenção das bebidas hidrossolúveis de soja saborizada com frutos do cerrado.

Foi utilizada escala hedônica estruturada de nove pontos, abrangendo de "desgostei muitíssimo" (1) a "gostei muitíssimo" (9) para avaliar as três formulações de bebida com EHS saborizadas com cagaita e mangaba [1) $10 \%$ mangaba; 2) $10 \%$ de cagaita; e 3) $5 \%$ de cagaita e $5 \%$ de mangaba]. $O$ teste de aceitação foi realizado em cabines individuais, com luz branca, no Laboratório de Análise Sensorial do Instituto Federal Goiano - Campus Urutaí. Participaram desta análise cinquenta provadores não treinados, selecionados apenas para degustar e apreciar o extrato hidrossolúvel de soja. A análise foi feita de forma monádica para avaliação dos atributos aparência, aroma, sabor, textura e impressão global. A intenção de compra também foi questionada com escala ancorada nos termos "certamente compraria" a "certamente não compraria".

Os resultados do teste de aceitação foram analisados por ANOVA/teste Tukey a 5\% de probabilidade, utilizando-se o software SENSOMAKER (NUNES; PINHEIRO, 2014). Para o teste de intenção de compra foi construído um histograma de distribuição percentual das notas dos consumidores.

\section{Resultados e Discussão}

A caracterização e atendimento aos padrões físicoquímicos das matérias-primas empregadas no processamento de alimentos e bebidas é um dos fatores que influenciam na qualidade e na aceitação sensorial do produto final. As polpas de mangaba e cagaita apresentaram $\mathrm{pH}$ inferiores a 4,0 (Tabela 1), isso confere alta acidez à polpa restringindo o crescimento de microrganismos patogênicos.

A legislação nacional que define os padrões de identidade e qualidade de polpa de frutas ainda não caracterizou a polpa de cagaita.

O conteúdo de sólidos solúveis (SS) no fruto está relacionado ao teor de açúcares, sendo que $85 \%$ dos sólidos solúveis corresponde à açúcares (CHITARRA; CHITARRA, 2005). A polpa de cagaita apresentou SS inferior à mangaba (Tabela 1) e também inferior aos SS determinados por Carneiro et al. (2015) em cagaitas da região oeste da Bahia (11,6\% de sólidos solúveis).

Os SS da polpa de mangaba determinados nesse estudo também são inferiores aos valores verificados por Santos et al. (2012) de 14,83 ${ }^{\circ}$ Brix e Carnelossi et al. (2004) de $15,2{ }^{\circ}$ Brix. As variações nos parâmetros físico-químicos das polpas de cagaita e mangaba são previstas, segundo Nascimento et al. (2014) por se tratar de plantas ainda não domesticadas.

Tabela 1. Valores médios e desvio padrão dos parâmetros físico-químicos das polpas.

\begin{tabular}{lrr}
\hline \multicolumn{1}{c}{ Parâmetros Avaliados } & Mangaba & \multicolumn{1}{c}{ Cagaita } \\
\hline pH & $3,55 \pm 0,03$ & $3,42 \pm 0,06$ \\
ATT (\% em ácido cítrico) & $0,88 \pm 0,09$ & $0,66 \pm 0,09$ \\
Sólidos Solúveis ( ${ }^{\circ}$ Brix) & $13,50 \pm 0,5$ & $10,33 \pm 0,58$ \\
Ratio (SS/ATT) & $15,35 \pm 0,72$ & $16,08 \pm 0,85$ \\
Umidade (\%) & $88,57 \pm 0,12$ & $81,31 \pm 0,08$ \\
Cinzas (\%) & $0,55 \pm 0,02$ & $0,23 \pm 0,07$
\end{tabular}

Fonte: Autores (2016). 
Ambas as polpas apresentaram ratio acima de 15, (15,35 para mangaba e 16,08 para cagaita) considerados valores elevados para Chitarra \& Chitarra (2005) e indicam que as polpas de mangaba e cagaita apresentam boas características para a industrialização de produtos adocicados, tais como, doces, geleias, picolés e sorvetes.

Os frutos carnosos e suculentos geralmente se caracterizam por polpa com elevada umidade (acima de $80 \%$ ) e nesse estudo a umidade da polpa de mangaba $(88,57 \%)$ foi superior à da cagaita $(81,31 \%)$. O elevado teor de água nas polpas de mangaba e cagaita, juntamente com a fragilidade da casca, tornam esses frutos altamente susceptíveis à deterioração enzimática e microbiana, fato que dificulta sua conservação in natura mas de outro modo favorece sua utilização na indústria em forma de bebidas lácteas, néctares, sucos, geléias, doces.

O conteúdo de cinzas está associado à matéria inorgânica do alimento, sendo assim, alimentos com alto conteúdo de água apresentam baixos valores resíduos incinerados, como as polpas de cagaita e mangaba (Tabela 1). O valor de cinzas determinado na polpa de mangaba foi próximo ao encontrado por Silva et al. (2008), de $0,58 \mathrm{~g} 100 \mathrm{~g}^{-1}$ de cinzas e para a cagaita foi inferior ao conteúdo de cinzas determinado por Camilo et al. (2014) de 0,28\% em cagaita.

Os valores encontrados para $\mathrm{pH}$ nas três formulações da bebida com extrato hidrossolúvel de soja foram superiores a 7 (Tabela 2), o que diferencia essa bebida de sucos e néctares de frutas os quais apresentam $\mathrm{pH}$ geralmente abaixo de 4,5. A utilização de EHS como diluente não caracteriza a obtenção de bebidas com $\mathrm{pH}$ baixo visto que acarretaria na precipitação de proteínas depreciando sensorialmente a bebida. Autores como Liutkevicius et al. (2016) também observaram pH próximo a 7,0 $(6,87)$ na formulação de uma bebida com EHS enriquecida com inulina

A acidez titulável não apresentou grande variação entre as formulações (Tabela 2), o que era de se esperar já que a quantidade de polpa de fruta adicionada nas três formulações é a mesma (10\%) variando apenas o tipo de polpa (mangaba/cagaita). A acidez máxima detectada foi de $0,2 \%$ valor semelhante ao determinado por Abreu et al. (2007) para bebida com extrato hidrossolúvel de soja saborizada com abacaxi.
O conteúdo de sólidos solúveis variou entre as formulações (Tabela 2) visto que os sólidos solúveis das polpas de cagaita e mangaba também são diferentes. Observa-se na formulação 2 , bebida saborizada com cagaita, o menor conteúdo de sólidos solúveis $17^{\circ}$ Brix, assim como a polpa de cagaita também apresentou SS inferior à mangaba. Em relação aos sólidos solúveis Tashima e Cardello (2003) apresentaram resultado de $10,00{ }^{\circ}$ Brix para extrato hidrossolúvel de soja comercial adoçado com sacarose tradicional, sendo este inferior ao encontrado neste estudo (Tabela 2). Os ingredientes inseridos nas formulações são responsáveis por essa diferença, visto que $1{ }^{\circ}$ Brix corresponde a $1,0 \mathrm{~g}$ de açúcar em $100 \mathrm{~mL}$ de solução, ao adicionar o açúcar, aumenta também o volume da solução.

As variações no ratio entre as formulações 1, 2 e 3 (Tabela 2) são decorrentes dos diferentes conteúdos de sólidos solúveis e acidez titulável das duas espécies frutíferas (cagaita e mangaba). Abreu et. al. (2007) obteve ratio de 85 para bebida com EHS saborizada com goiaba. Vale ressaltar que o conteúdo de açúcar incorporado à bebida também influenciará o valor do ratio.

Os resultados de sólidos totais não apresentaram grande variação entre as formulações (Tabela 2) e foram bastante superiores aos resultados apresentados por Jaekel et al. (2010) em estudos com bebida composta de $70 \%$ de extrato de soja e $30 \%$ de extrato de arroz, apresentando $10,13 \%$ de sólidos totais. A diferença entre o estudo citado acima e o presente estudo é justificada pela adição da polpa de fruta utilizada neste estudo, o que difere da formulação com apenas extrato de soja e de arroz.

O teste de aceitação das três formulações de bebida com extrato hidrossolúvel de soja saborizadas com mangaba (Formulação 1), cagaita (Formulação 2) e mangaba/cagaita (Formulação 3), Figura 2, não indicou diferença estatística entre as mesmas na aceitação dos atributos aparência, aroma, sabor, textura e impressão global. A maioria das médias dos diferentes atributos avaliados, nas três formulações, estão próximas a nota 7 que corresponde ao termo "gostei moderadamente" na escala hedônica estruturada.

Tabela 2: Valores médios e desvio padrão dos parâmetros físico-químicos das bebidas.

\begin{tabular}{llll}
\hline Parâmetros Avaliados & Formulação 1 & Formulação 2 & Formulação 3 \\
\hline pH & $7,97 \pm 0,05$ & $7,33 \pm 0,05$ & $7,20 \pm 0,06$ \\
ATT (\% em ácido cítrico) & $0,16 \pm 0,01$ & $0,20 \pm 0,01$ & $0,19 \pm 0,00$ \\
Sólidos Solúveis ( ${ }^{\circ}$ Brix) & $19,50 \pm 0,00$ & $17,00 \pm 0,00$ & $18,00 \pm 0,00$ \\
Ratio (SS/ATT) & $124,90 \pm 8,83$ & $83,79 \pm 4,92$ & $94,74 \pm 0,00$ \\
Sólidos Totais (\%) & $17,27 \pm 0,10$ & $17,03 \pm 0,12$ & $17,75 \pm 0,17$ \\
Cinzas (g\%) & $0,39 \pm 0,03$ & $0,40 \pm 0,08$ & $0,36 \pm 0,06$ \\
\hline
\end{tabular}

Fonte: Autores (2016). 


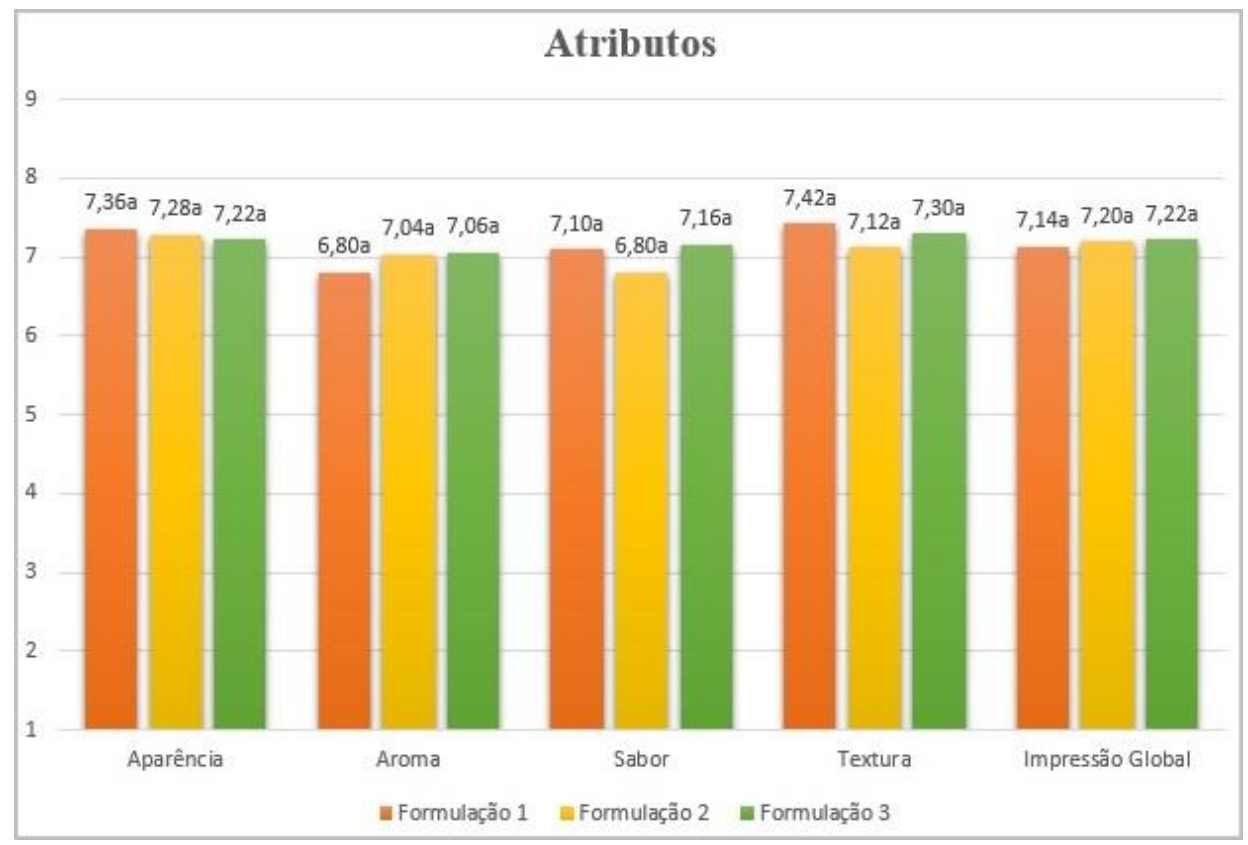

Figura 2: Histograma das médias de aceitação das bebidas com extrato hidrossolúvel de soja saborizada com frutos do Cerrado. Fonte: Autores (2016).

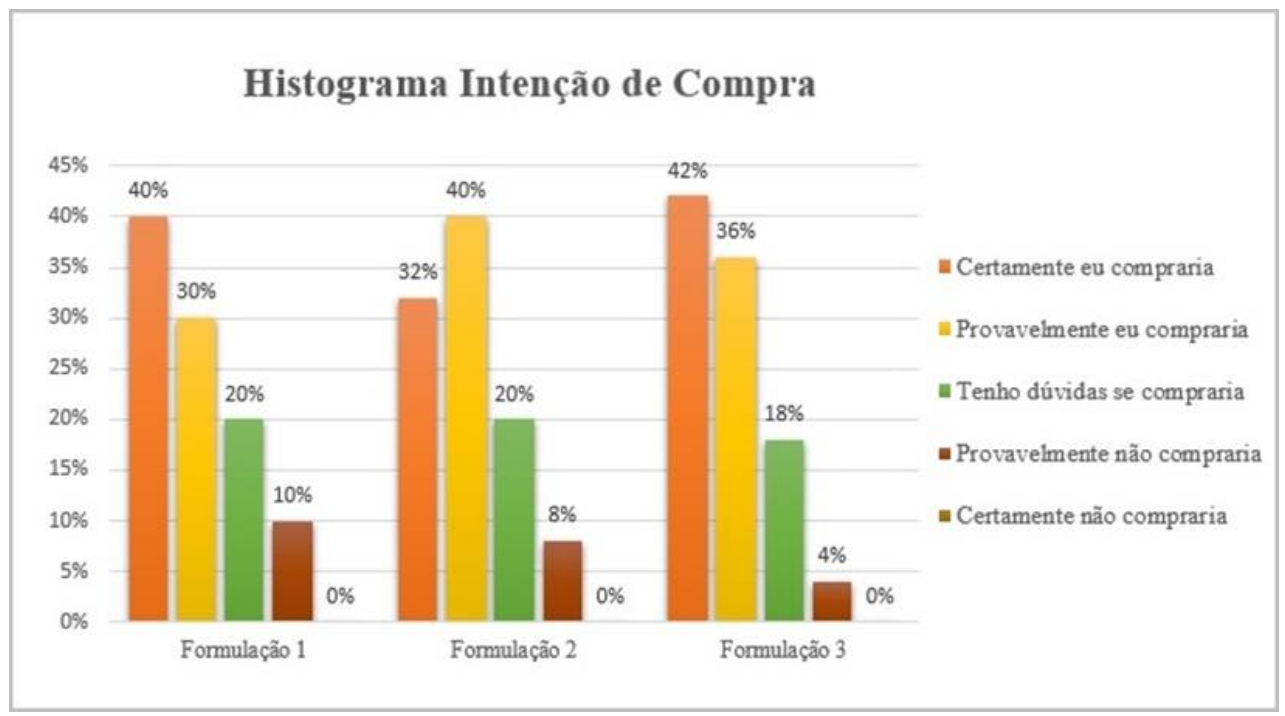

Figura 3: Histograma de intenção de compra. Fonte: Autores (2016).

A Formulação 3 que corresponde à bebida com extrato hidrossolúvel de soja mista de cagaita e mangaba apresentou todas as médias dos atributos avaliados superiores a 7 , indicando que a combinação das polpas foi positivo na aceitação sensorial.

Assumpção et al. (2013) obtiveram para um néctar misto de mangaba e cagaita resultado de avaliação sensorial próxima ao encontrado nesse estudo, com média de aceitação para impressão global de 7,96.

Silva et al. (2015) na elaboração e avaliação sensorial de um leite fermentado saborizado com diversos frutos do Cerrado observaram que a formulação saborizada com mangaba elaborada com menor quantidade de polpa (4\%) teve maior aceitação. Apesar dos frutos mangaba e cagaita serem típicos da região, ainda é incipiente o consumo dos mesmos pela população urbana. O desconhecimento do sabor e aroma peculiar desses frutos regionais pode ser um fator que influencia na aceitação sensorial de industrializados saborizados com tais.

$\mathrm{Na}$ intenção de compra verifica-se que as três formulações apresentaram atitude de compra positiva, que corresponde aos termos "certamente compraria", e "provavelmente compraria", superior a 70\% (Figura 2), o que indica possível sucesso na comercialização da bebida. O uso do extrato hidrossolúvel de soja como diluente não interferiu negativamente na intenção de compra das formulações desenvolvidas nesse estudo. A Formulação 3, com o blend de polpas de cagaita e mangaba, apresentou maior intenção de compra (78\%). 


\section{Conclusões}

Quanto às análises físico-químicas, ambas as polpas apresentaram-se dentro dos limites encontrados em outros estudos analisados. As variações nos conteúdos de sólidos solúveis, acidez titulável e ratio nas formulações são referentes às diferentes espécies frutíferas utilizadas na saborização das bebidas.

A elaboração de bebidas com extrato hidrossolúvel de soja saborizadas com mangaba e cagaita mostraramse viáveis com boas médias de aceitação sensorial para os atributos avaliados (aparência, aroma, sabor, textura e intenção de compra). A formulação saborizada com o blend de polpas de cagaita e mangaba (5\% de cagaita e $5 \%$ de mangaba) apresentou as maiores médias sensoriais de aceitação e também maior porcentagem de intenção de compra positiva.

As bebidas elaboradas são uma opção para industrialização e ampliação do consumo de frutos do Cerrado bem como para a diversificação de produtos à base de extrato hidrossolúvel de soja.

\section{Agradecimentos}

A autora agradece ao Instituto Federal Goiano pela concessão da bolsa e apoio financeiro recebido e à Universidade Estadual de Goiás - Unidade Universitária de Ipameri pela doação dos frutos.

\section{Referências Bibliográficas}

ABREU, C. R. A.; PINHEIRO, A. M.; MAIA, G. A.; CARVALHO, J. M.; SOUSA, P. H. M. Avaliação química e físico-química de bebidas de soja com frutas tropicais. Alimentos e Nutrição, Araraquara-SP, v. 18, n. 3, p. 291-296, 2007.

\section{ASSOCIATION OF OFFICIAL ANALYTICAL CHEMISTS. AOAC. Official methods of analysis. 16 ed. Washington:,DC, EUA, 1997.}

ASSUMPÇÃO, C. F.; BACHIEGA, P.; SANTANA, A. T. M. C.; MORZELLE, M. C.; VILAS BOAS, B. M., DE SOUZA, E. C. Néctar misto de mangaba (Hancoria speciosa gomes) e cagaita (Eugenia dysenterica): perfil sensorial e características físico-químicas. Revista Brasileira de Produtos Agroindustriais, Campina Grande-SP, v. 15, n. 3, p. 219-224, 2013.

CAMILO, Y. M. V.; SOUZA, E. R. B.; VERA, R.; NAVES, R. V. Fenologia, produção e precocidade de plantas de Eugenia dysenterica visando melhoramento genético. Revista de Ciências Agrárias, Lisboa, v. 36, n. 2, p. 192-198, 2013.

CAMILO, Y. M. V.; SOUZA, E. R. B.; VERA, R.; NAVES, R. V. Caracterização de frutos e seleção de progênies de cagaiteiras (Eugenia dysenterica DC.). Científica, Jaboticabal-SP, v. 42, n. 1, p.1-10, 2014.
CARNEIRO, J. O.; SOUZA, M. A. A.; RODRIGUES, Y. J. M.; MAPELI, A. M. Efeito da temperatura e do uso de embalagem na conservação pós-colheita de frutos de cagaita (Eugenia dysenterica dc.). Revista Brasileira de Fruticultura, Jaboticabal-SP, v. 37, n. 3, p. 568-577, 2015.

CARNElOSSI, M. A. G.; TOLEDO, W. F. F.; SOUZA, D. C. L.; LIRA, M. L.; SILVA, G. F.; JALALI, V. R. R.; VIÉGAS, P. R. A. Conservação pós-colheita de mangaba (Hancornia speciosa Gomes). Ciência e Agrotecnologia, Lavras - MG, v. 28, n. 5, p. 1119-1125, 2004.

ChITARRA, M. I. F.; CHITARRA, A. B. Pós-colheita de frutos e hortaliças: fisiologia e manuseio. $2^{\mathrm{a}}$ ed., Lavras-MG: UFLA, 2005.

JAEKEL, L. Z.; RODRIGUES R. S.; SILVA, A. P. Avaliação físico-química e sensorial de bebidas com diferentes proporções de extratos de soja e de arroz. Ciência e Tecnologia de Alimentos, Campinas-SP, v. 30, n. 2, p. 342348 , 2010. DOI: http://dx.doi.org/10.1590/S010120612010000200009.

LIUTKEVICIUS, A.; SPEICIENE, V.; VAICIULYTEFUNK, L.; MIEZELIENE, A.; ALENCIKIENE, G.; ABARAVICIUS, A.; BAGDONAITE, L.; JABLONSKIENE, V.; KAMINSKAS, A. An Inulin-Enriched Soy Drink and Its Lowering Effect on Oxidized Low Density Lipoproteins in Healthy Volunteers. Polish Journal Food Nutrition Sciences, Olsztyn, v. 66, n. 1, p. 37-41, 2016.

MARTINS, M. T. S. Caracterização química e nutricional de plasteína produzida a partir de hidrolisado pancreático de isolado protéico de soja. $n$. 25, Campinas-SP: Boletim da Sociedade Brasileira de Ciência e Tecnologia de Alimentos, 2005, 683 p.

NASCIMENTO, R. S. M.; CARDOSO, J. A.; COCOZZA, F. D. M. Caracterização física e físico-química de frutos de mangabeira (Hancornia speciosa Gomes) no oeste da Bahia. Revista Brasileira de Engenharia Agrícola Ambiental, Campina Grande-SP, v. 18 n. 8, p. 856 - 860, 2014.

NUNES, C. A.; PINHEIRO, A. C. M. Senso Maker, version 1.9. UFLA, Lavras - MG, 2014.

PERFEITO, D. G. A.; CARVALHO, N. LOPES, M. C. M.; SCHMIDT, F. L. Caracterização de frutos de mangabas (Hancornia speciosa Gomes) e estudo de processos de extração da polpa. Revista de Agricultura Neotropical, Cassilândia - MS, v. 2, n. 3, p. 1-7, 2015.

SANTOS, J. T. S.; SOARES, F. S. C.; SOARES, D. S. C.; CAMPOS, A. F. P.; CARNELOSSI, M. A. G.; NUNES, T. P.; OLIVEIRA JÚNIOR, A. M. Avaliação de mangaba liofilizada através de parâmetros físico-químicos. Scientia Plena, São Cristóvão-SE, v. 8, n. 3, p. 1-5, 2012.

SCARIOT, A.; RIBEIRO, J. F. Boas práticas de manejo para o extrativismo sustentável da Cagaita, Brasília-DF: Embrapa Recursos Genéticos e Biotecnologia, v. 1, 2015, 9 p.

SILVA, D. B.; SILVA, J. A.; JUNQUEIRA, N. T. V.; ANDRADE, L. R. M. Frutas do cerrado. Brasília-DF: Embrapa Informação Tecnológica, 2001. 179 p.

SILVA, M. A. P.; VIEIRA, N. F.; MARTINS, Y. A. A.; ARAÚJO, V. F. P.; GONÇALVES, D. S., MOURA, L. C.; 
PLÁCIDO, G. R.; CARVALHO, B. S. Sensory profile of fermented milk drinks flavored with fruits from the Brazilian Cerrado. African Journal of Food Science, Nairobi-Quénia, v. 9 (6), p. 379-389, 2015.

SILVA, M. R.; SANTOS JÚNIOR, R. T. O.; FERREIRA, C. C. C. Estabilidade da vitamina c em cagaita in natura e durante a estocagem da polpa e refresco. Pesquisa Agropecuária Tropical, Goiânia - GO, v. 38, n. 1, p. 53-58, 2008.

SILVA, S.; H. TASSARA. Frutas no Brasil. $5^{\text {a }}$ ed. São Paulo-SP: Editare, v. 3, 2003, 15 p.
TASHIMA, E. H.; CARDELlO, H. M. A. B. Perfil sensorial de extrato hidrossolúvel de soja (Glicine Max L. Merril) comercial adoçado com sacarose e com sucralose. Boletim do Centro de Pesquisa de Processamento de Alimentos, Curitiba-PR, v. 21, n. 2, 2003, 409-428 p.

VENTURINI FILHO, W. G. Bebidas alcoólicas - Ciência e tecnologia. São Paulo-SP: Blucher, 2010, 461 p. 